University of Louisville

ThinkIR: The University of Louisville's Institutional Repository

Electronic Theses and Dissertations

$1-1927$

\title{
The preparation of derivatives related to novocain.
}

Helen Peil

University of Louisville

Follow this and additional works at: https://ir.library.louisville.edu/etd

\section{Recommended Citation}

Peil, Helen, "The preparation of derivatives related to novocain." (1927). Electronic Theses and Dissertations. Paper 1108.

https://doi.org/10.18297/etd/1108

This Master's Thesis is brought to you for free and open access by ThinkIR: The University of Louisville's Institutional Repository. It has been accepted for inclusion in Electronic Theses and Dissertations by an authorized administrator of ThinkIR: The University of Louisville's Institutional Repository. This title appears here courtesy of the author, who has retained all other copyrights. For more information, please contact thinkir@louisville.edu. 
UNIVERSITY OF LOUISVILIE

THE PREPARATION OF DERIVATIVES RELATED TO NOVOCAIN

\author{
A. Dissertation \\ Submitted to the Faculty \\ Of the Graduate School of the College of Liberal Arts \\ In Partial Fulfillment of the \\ Requirements for the Degree \\ of Naster of Science
}

Department of Chemistry

By

Helen Peil 


\section{CONTENTS}

\section{Part 1}

THE PREPARATION OF DERIVATIVES RELATED TO NOVOCAIN

1. Introduction 1

2. Experiments 7

3. Conclusions 17

4. Bibliography 18

\section{Part 2}

THE OXIDATION OF n-BUTYL THIOCYANATE WITH NITRIC ACID

1. Introduction 19

2. Experiments 20

3. Conclusions 28

4. Bibliography 29 
INTRODUCTION 
PREPARATION OF DERIVATIVES REIATED TO NOVOCAIN

The study of the relationship between chemical constitution

and physiological effect embraces many very interesting problems which are, however, frequently difficult to solve. In the investigation of any drug the first step is to determine the principle to which the physiological effect is due, and then by ana.1ysis and synthesis assign the correct chemical constitution to this principle. When the chemical constitution is definitely known, other compounds of a similar structure may be prepared, and their physiological action compered with the original drug. By this means it is sometimes possible to prepare drugs which possess the prinoiple desired in the natural product, but which do not have certein minor harmful physiological effects which were in the natural product. Drugs, to be useful, must also possess certain other properties such as solubility, stability during sterilization by boiling, and a minimum irritant action. All these properties in the original drug may frequently be improved upon by the chemist who can vary the chemical structure in the correct way.

An interesting illustration of such a compound is novocaine, which, though possessing the same locel anaesthetic effect as cocaine, newer-the-less lacks the harmful toxic properties present in cocaine.

After much investigation it was shown that the local 
anaesthetic action of cocaine was due to the fact that an

amino alkyl ester was present. The cocaine molecule has the following structure.

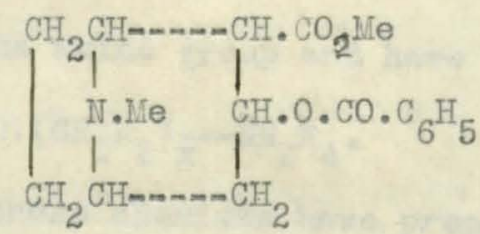

The carboxy methyl group could not have caused the anaesthetic action, for it is not present in tropacocaine:<smiles>[R9]OC1CC2CCCC(C1)N2O</smiles>

which possesses local anaesthetic properties. The presence of a bridged or simpld ring containing a nitrogen atom is also unnecessary, for eucaine (I) which possesses a simple, not a bridgẹd ring, and stovaine(2) alypine (3) and novocaine (4) which contain no such ring, all have locel anaesthetic properties.

(1)<smiles>CC1CCC(OC(=O)O)CC(C)N1</smiles>

(3)

$$
\left.\right|_{\mathrm{CH}_{2} \mathrm{~N} \cdot\left(\mathrm{CH}_{3}\right)_{2}} ^{\mathrm{CH}_{2} \mathrm{H}_{5} \mathrm{C} \cdot\left(\mathrm{CH}_{3}\right)_{2} \cdot 0 \cdot \mathrm{CO} \cdot \mathrm{C}_{6} \mathrm{H}_{5}}
$$

(2)

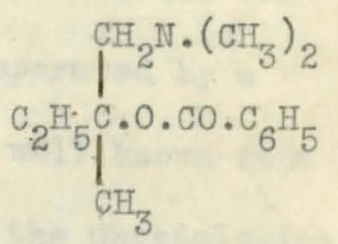

$$
\left(\mathrm{C}_{2} \mathrm{H}_{5}\right)_{2} \mathrm{~N} \cdot \mathrm{CH}_{2} \mathrm{CH}_{2} \mathrm{O} \cdot \mathrm{CO} \cdot \mathrm{C}_{6} \mathrm{H}_{4} \mathrm{NH}_{2}(\mathrm{p})
$$

From a study of all these compounds the conclusion was reached 
that the pjysiological action was caused by the amino alkyl ester structure found to be present in each compound. Anino alkyl esters are as a rule formed by the action of an acid on an alcohol containing the amino group and have the following general formula - R.CO.O. $\left(\mathrm{CR}_{1} \mathrm{R}_{2}\right) \mathrm{x}^{--\mathrm{NR}_{3} \mathrm{R}_{4}} \cdot$

By studies such as these chemists have prepared substances having the desired local anaesthethe properties, but having either very little toxicity or else as in the case of norocaine, lacking toxic properties entirely. The following table shows these results.

Compound Toxicity Ansesthetic action Irritant action

$\begin{array}{lllc}\text { cocaine } & 1 & 1 & + \\ \text { eucaine } & 0.4 & 1 & ++ \\ \text { stovaine } & 0.6 & 1 & ++ \\ \text { alypine } & 0.9-0.5 & 1 & +t++ \\ \text { novocaine } & 0.3-0.5 & 0.1 & -\end{array}$

Considering the structure of novocaine $\left(\mathrm{C}_{2} \mathrm{H}_{5}\right)_{2} \mathrm{~N} \cdot \mathrm{CH}_{2} \mathrm{CH}_{2} \mathrm{O} \cdot \mathrm{CO} \cdot \mathrm{C}_{6} \mathrm{H}_{5} \mathrm{NH}_{2}$ one notices that the a.lkamine structure found in compounds having local anaesthetic properties is present. There are also two nitrogen atoms present which are separated by a carbon chain of 7 cerbon atome. Now it is a well known fact that the length of the carbon chain effects the physiological " properties which a compound may posiess. Thus the ethyl group generally exerts the highest effeet in compounds having local anaesthetic properties, although there are instances in which the butyl group or some other group exerts the highest 
effect. It would be interesting, therefore, to prepare compounds related to some compound already known to possess certâin physiologicàl properties and having a similar structure except that the crrbon side chain is varied. The physiological effects of these compounds could then be compared and some conclusion draw as to the influence exerted by the length of the carbon chain.

A. summary of the experiments dorie upon compounds having local anaesthetic properties shows that they possess in general the following characteristics.

(1) The acyl group is usually aromatic.

(2) The amino group may be secondary or tertiary, and may be associated with a simple or a bridged ring complex.

(3) The alcohol group may be primary, secondary, or tertiary, and may separate the acyl and amino groups by a chain of either 2 or 3 carbon atoms. My problem was to prepare derivatives of quinoline carboxylic and picolinic acids by combining the freshly prepared chlorides with diethyl amino ethanol and with diethyl propanol. In this way compounds would be prepared whose only differenoe would lie in the number of cerbon atoms situated between the two nitrogen atoms present. For instance a-quinoline carboxylic acid would give 1 
derivatives with diethylamino ethanol and 1 derivative with diethylamino propanol. The g-acid would yield 2 simelar derivatives. The formulae for the aminoalkyl esters to be prepared are as follows.
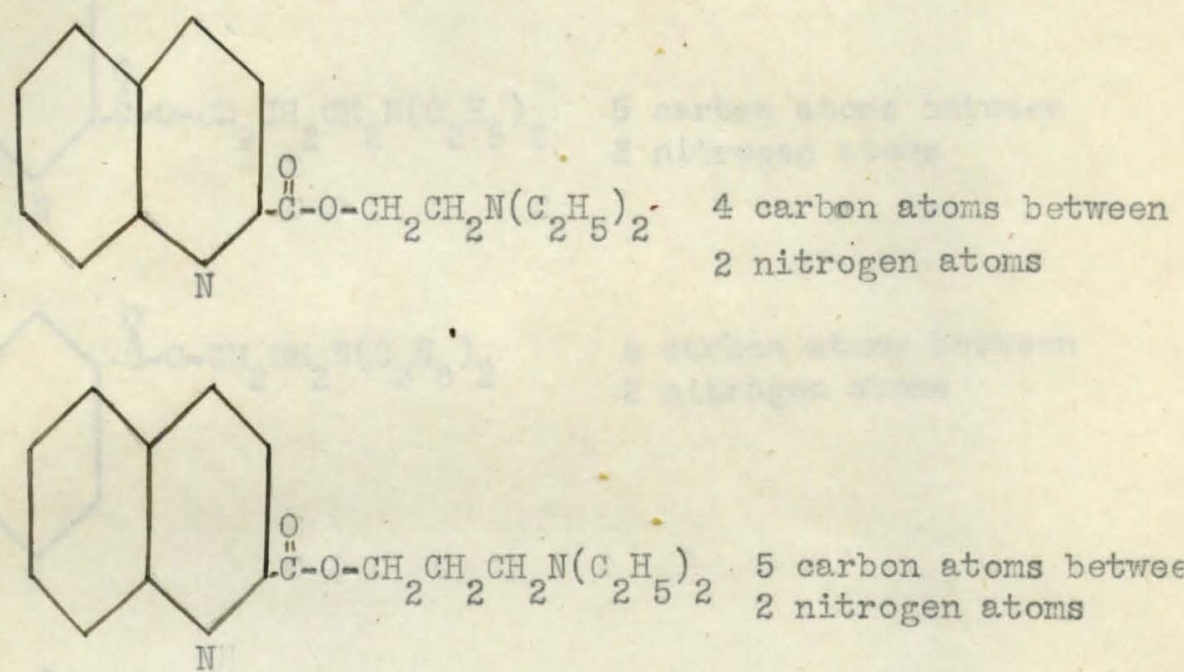

5 carbon atoms between 2 nitrogen a.toms

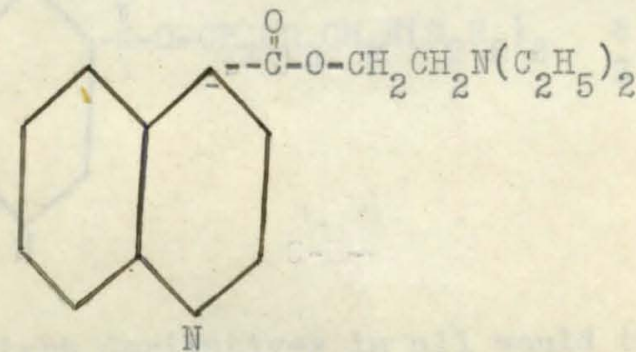

5 carbon atoms between 2 nitrogen atoms

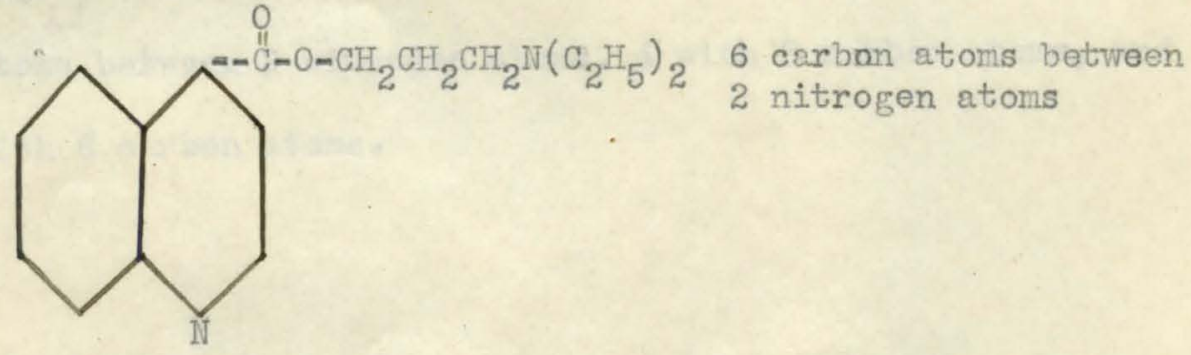

The derivatives of the picolinic acids would also be four in number and would have the following formulae. 


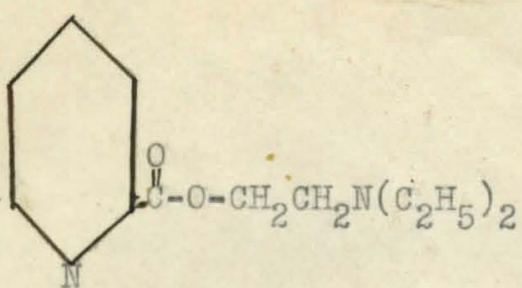

4 carbon atoms between

2 nitrogen atoms

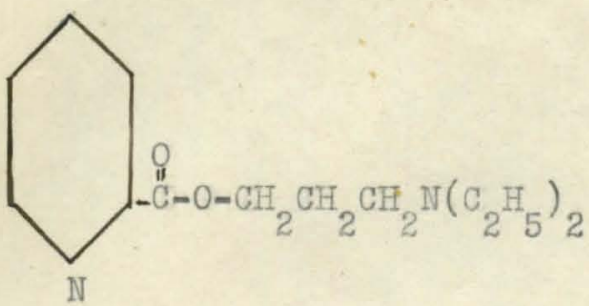

5 carbon atoms between

2. nitrogen atoms

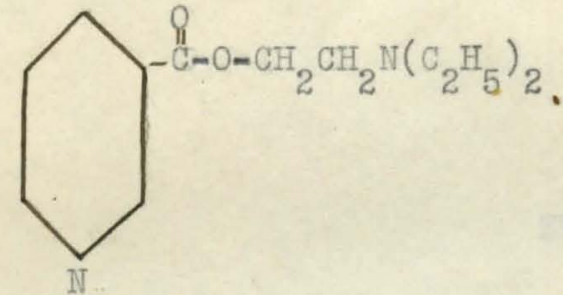

5 carbon atoms between

2 nitrogen atoms

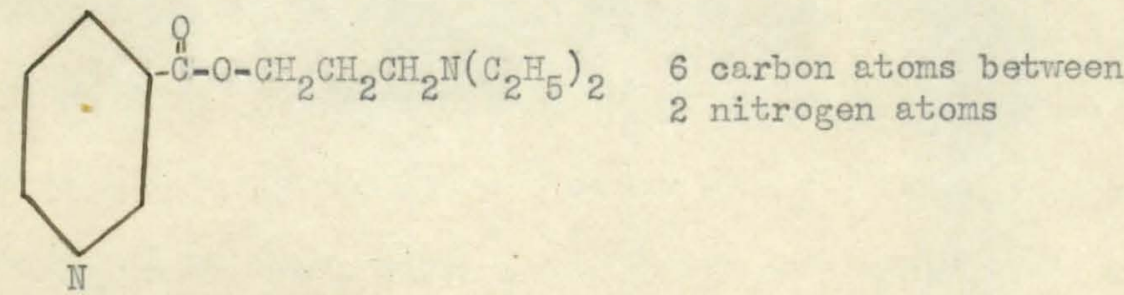

Elght derivatives in 2.11 would thus be prepared, 2 with 4 carbon atoms between 2 nitrogen atoms, 4 with 5 carbon atoms, and 2 with 6 carbon atoms . 

***

EXPERIUENTAL

$* * *$

Preparation of a- ouinoline Carboxylic Acid
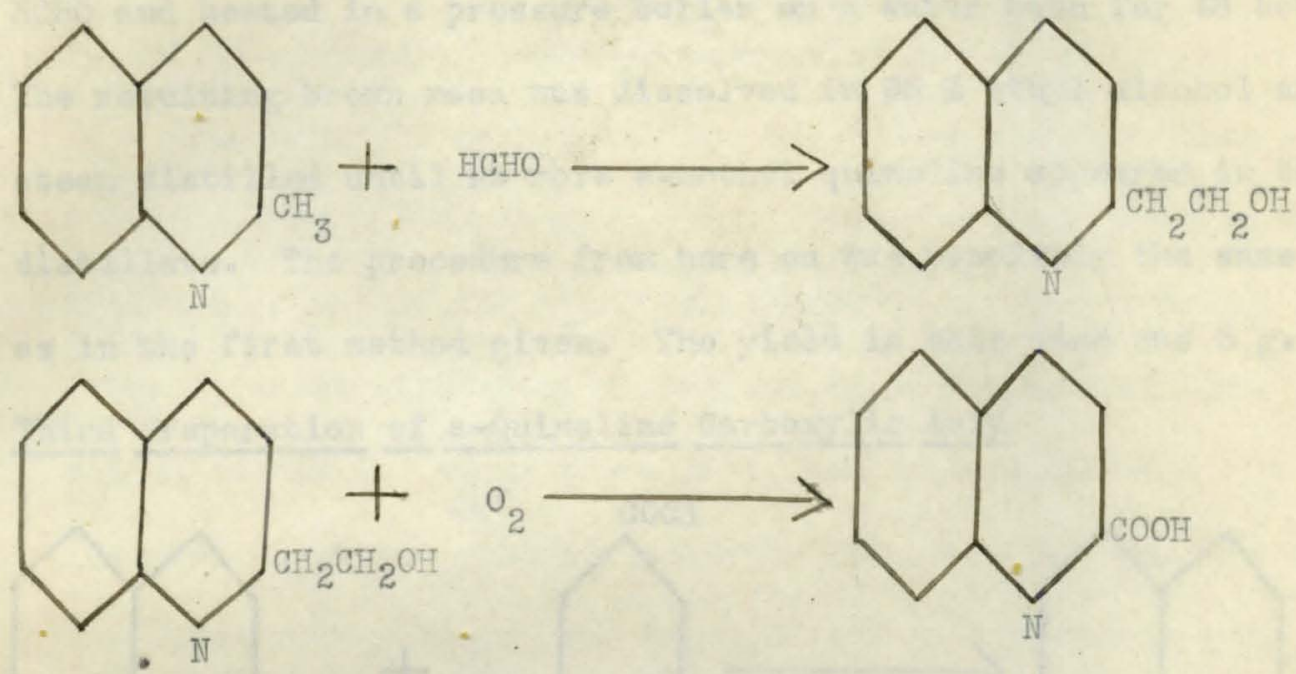

$20 \mathrm{~g}$. of a-methyl quinoline were mixed with $18 \mathrm{~g}$. of $40 \%$ HCHO and $20 \mathrm{cc}$ of $50 \%$ ethyl alcohol and refluxed on a water bath for 14 hours. A steam distillation wis then made until no more methyl quinoline was found when the distillate was tested with $\mathrm{NaOH}$. The resulting mass, after being dried on a water bath, was dissolved in $450 \mathrm{cc}$. of nitric acid ( $\mathrm{sp} \cdot \mathrm{g} \cdot 1.4)$. When the reaction ceased, the mixture was heated for 10 hours on a water bath and then evaporated to dryness. The lead salt was made by dissolving the acid in water, neutralizing with amonium hydroxide, acidifying with acetic acid and then adding a concentrated solution of lead acetate. The lead selt was filtered, washed and decomposed with hydrogen sulfide. Upon filtering and evaporating the filtrate, a-quinoline carboxylic acid crystallized out on long yellow needles. The 
yield by this method was so poor as to be negligable.

$20 \mathrm{~g}$. of a-methyl quinoline were mixed vith $30 \mathrm{~g}$. of $40 \%$ HCHO and heated in a pressure boiler on a water bath for 48 hours. The resulting brown mass was dissolved in $96 \%$ ethyl alcohol and steam distilled until no more a-methyl quinoline appeared in the distillate. The procedure from here on was precisely the same as in the first method given. The yield in this case was $5 \mathrm{~g}$. Third Preparation of a-Quinoline Carboxylic Acid
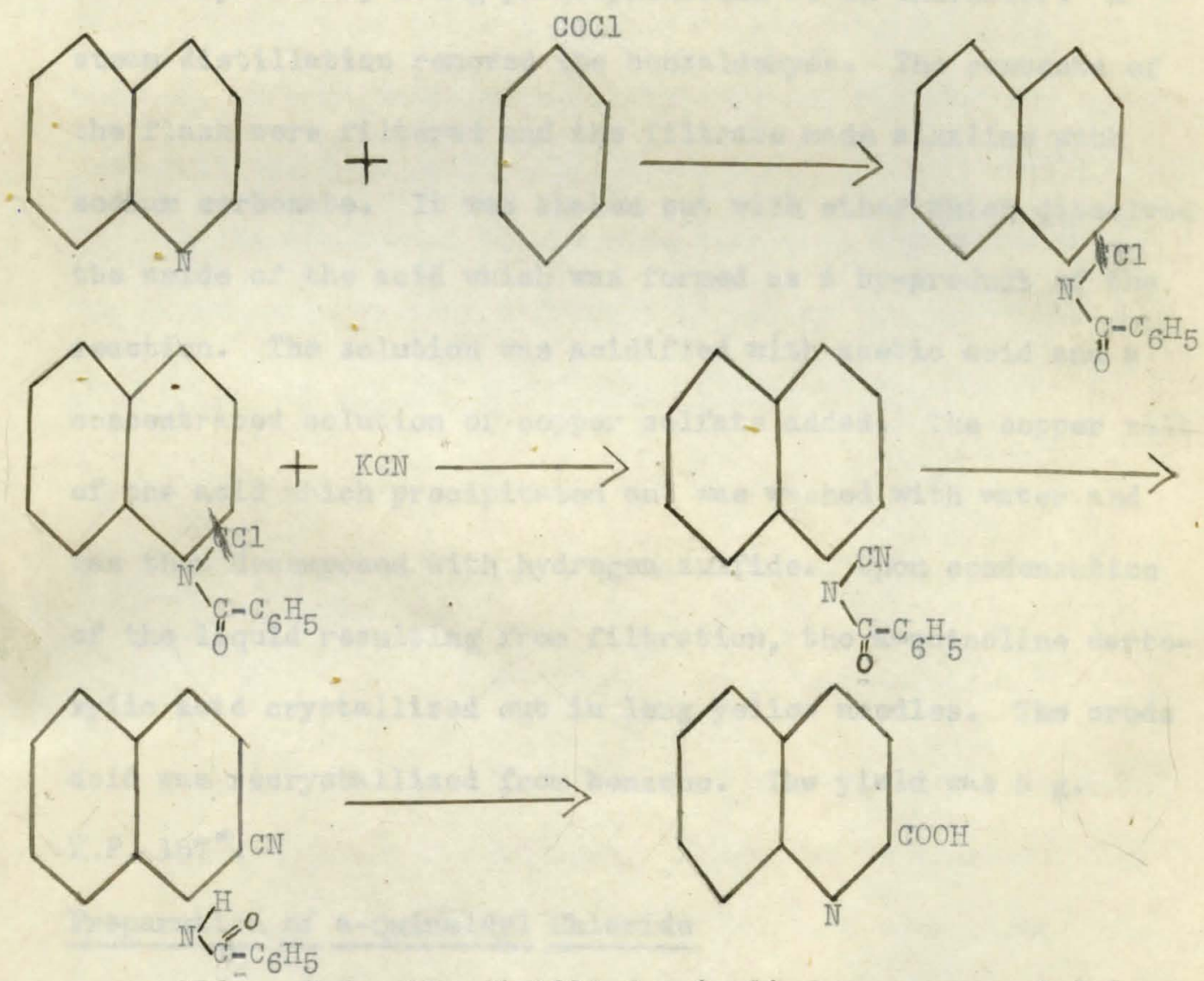

20 g. of freshly distilled quinoline were suspended in a solution of $30 \mathrm{~g}$. of potassium cyanide in $200 \mathrm{gc}$. Water. $45 \mathrm{~g}$. of benzoyl chloride were then added with shaking until the smell of chlorine diseppeared. The tempereture wes kept between 20 to 32 degrees. The precipitate was decanted and shaken out 
with dilute hydrochloric acid until it was solid. It was then filtered and shaken out with ether until it was solid. The yield of benzoylcyandihydroquinoline was $25 \mathrm{~g}$.

The benzoyldihydroquinoline was pulverized and mixed with $200 \mathrm{cc}$. of $36 \%$ hydrochloric acid. This was left standing in a closed container for a day and shaken from time to time. After diluting with water it was exactaly neutralized with sodium hydroxide, using phenolphthalein as an indicator. A steam distillation removed the benzaldehyde. The contents of the flask were filtered and the filtrate made alkaline with sodium carbonate. It was shaken out with ether which dissolved the amide of the acid which was formed as a by-product of the reaction. The solution was acidified with acetic acid and a concentrated solution of copper sulfate added. The copper salt of the acid which precipitated out was washed with water and was then decomposed with hydrogen sulfide. Upon condensation of the liquid resulting from filtration, the a-quinoline carbexylic acid crystallized out in long yellow needles. The crude acid was recrystallized from benzene. The yield was $5 \mathrm{~g}$. M.P. $157^{\circ}$.

Preparation of a-Quinaldy l Chloride
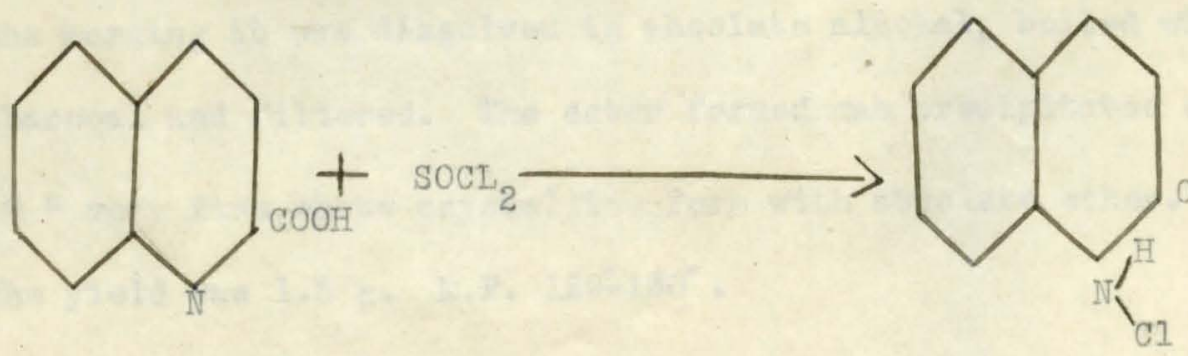
$4 \mathrm{~g}$. of the a-quinoline carboxylic acid thus prepered were refluxed on a wer bath with $32 \mathrm{cc}$. thionyl chloride until all the acid was dissolved. The excess thionyl chloride was evaporated off and the residue dissolved in hot benzene, cooled, and kept in the ice box over night. The chloride which precipitated out was filtered off in the morning and the remaining benzene solution was then condens- ? ed on a water bath still further. On standing again in the ice box, more chloride crystallized out and was filtered off. The yield was 3 g. M.P. $175^{\circ}$.

A red dye formed at the same time that the chloride was formed made it very difficult to purify the chloride. Preparation of Diethyl Amino Ethyl Quinolinate

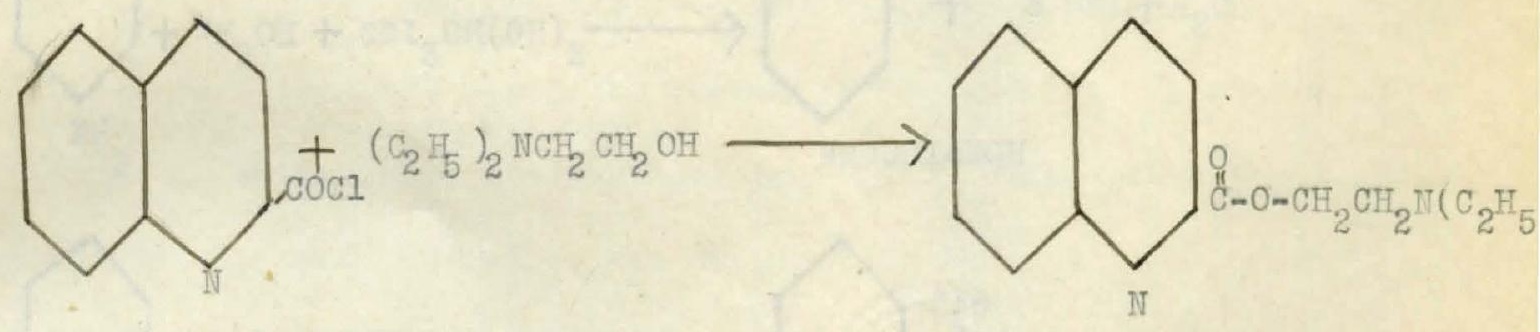

$3 \mathrm{~g}$. of the unpurified chloride were refluxed on a water bath with $1.3 \mathrm{~g}$. of diethylamino ethanol for 45 minutes. The flask was then stoppered and allowed to stand over night. In the morning it was dissolved in absolute alcohol, boiled with charcoal and filtered. The ester formed was precipitated out in a very fine white crystalline form with absolute ether. The yield vras 1.5 g. M.P. $129^{\circ}-130^{\circ}$. 
Preparation of Diethyl Amino Propyl Quinolinate

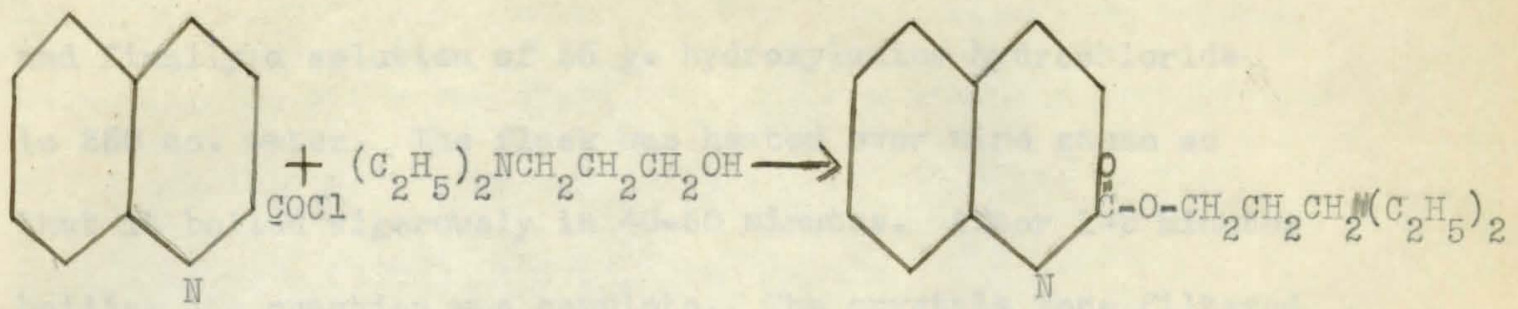

2. g. of a-quineldyl chloride were refluxed with $1.5 \mathrm{~g}$. of diethylamino propanol until the reaction was couplete. Then absolute othyl alcohol was added and the ester was precipitated out with ether. The flask was put in the ice box and the ester came out as a reddish oil which will probably be a solid after purifieation.

Preparation of Isatin
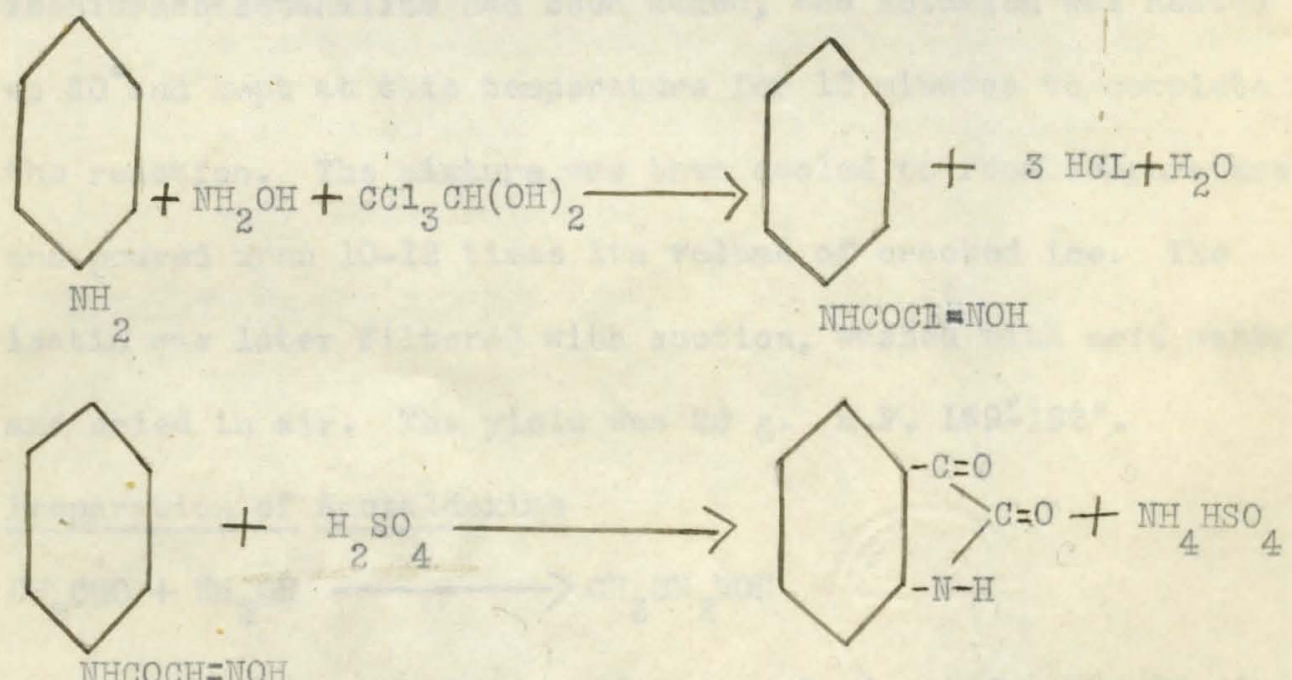

$45 \mathrm{~g}$. of chloral hydrate and $600 \mathrm{cc}$. of water were placed in a three liter R.B. Plask. To this solution were then added in order $650 \mathrm{~g}$. crystallized sodium sulfate, a solution of $23.2 \mathrm{~g}$. eniline in $150 \mathrm{cc}$. water to which $21.5 \mathrm{cc}$. concentrated hydrochlor- 
ic acid ( $\mathrm{sp} \cdot \mathrm{g} \cdot 1.19)$ had been added to dissolve the amine, and finally a solution of $55 \mathrm{~g}$. hydroxylamine hydroohloride in $250 \mathrm{co}$. water. The flask was heated over wire gauze so that it boiled vigorously in 40-50 minutes. Aftor 1-2 minutes boiling the reaction was complete. The crystels were filtered and air dried. The yield wres $36 \mathrm{~g}$. M.P. $175^{\circ}$.

$300 \mathrm{~g}$. of concentrated sulfuric acid (sp.g. 1.84) were warmed to $50^{\circ}$ in a 1 liter R.B. flask fitted with a mechanical stirrer and to this, $37 \mathrm{~g}$. of dry isonitrosoacetanilide were added at such a rate as to keep the temperature between $60^{\circ}$ $70^{\circ}$. External cooling was applied at this stage, so that the reaction could be carried out more rapidly. After all the isonitrosoacetanilide had been added, the solution was heated to $80^{\circ}$ and kept at this temperature for 10 minutes to complete the reaction. The mixture was then cooled to room temperature and poured upon 10-12 times its volume of oracked ice. The isatin was later filtered with suction, washed with cold water, and dried in air. The yield was $26 \mathrm{~g}$. M.P. $189^{\circ}-192^{\circ}$. Preparation of Acetaldoxime $\mathrm{CH}_{3} \mathrm{CHO}+\mathrm{NH}_{2} \mathrm{OH} \longrightarrow \mathrm{CH}_{3} \mathrm{CH}_{2}{ }_{2} \mathrm{IOH}$

A solution of $16.2 \mathrm{~g}$. of hydroxylamine hydrochloride in $15 \mathrm{cc}$. water and $12.7 \mathrm{~g}$. sodium carbonate in $30 \mathrm{ce}$. water were put in a freezing mixture in a R.B. flask. Then $10 \mathrm{~g}$. acotaldehyde in $5 \mathrm{cc}$. weter were added by means of seperatory funnel. The mixture was allowed to stand 15 hours and a set- 
urated solution of sodium chloride was added. This was shaken out 8 times with $75 \mathrm{cc}$ ether. After being dried over calcium chloride, the ether was distilled off, and then the acetaldoxime was distilled over between $112^{\circ}-114^{\circ}$. The yield was $15 \mathrm{cc}$. Preparation of g-quinoline carboxylic acid<smiles>CC(OCCOC(=O)O)OC1CCC2CCCCC2CC1</smiles>

A solution of $10 \mathrm{~g}$. of isatin in an excess of $40 \%$ potassium hydroxide was heated with $8 \mathrm{~g}$. of acetaldoxime on a water bath for several hours. The potassium salt of the acid precipitated out, was filtered and ashed with $96 \%$ ethyl alcohol. The salt was decomposed with acetic acid and the free acid precipitated out. It was recrystallized from water. The yield was very small. M.P. $251^{\circ}$.

Preparation of a-Picolinic Acid

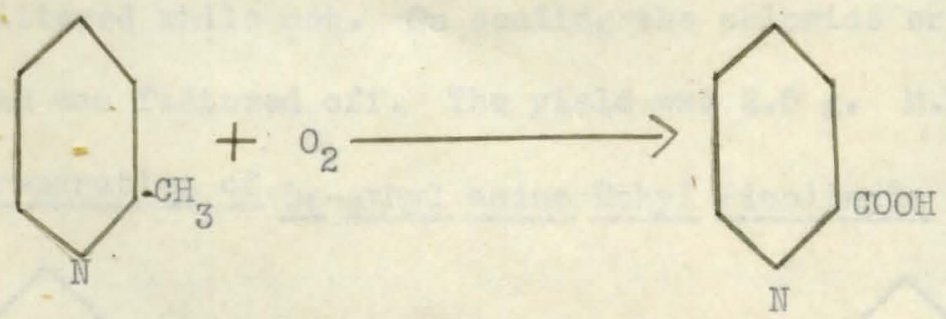

Into $170 \mathrm{~g}$. potassium permanganate in 4 liters of water at a temperature of $70^{\circ}-80^{\circ}, 50 \mathrm{~g}$. of a-picoline were dropped through a separatory funnel. This mixture was heated on a water bath until the color of the potassium permanganate nearTy disappeared. After filtration the solution was concentrated. 
to a small volume on a water bath and then acidified with dilute sulfuric acid. A concentrated solution of $\frac{c}{2}$ opper sulfate was then added and the copper selt of the acid which precipitated out was washed and then decomposed with hydrogen sulfide. After filtration and partial evaporation, the a-picolinic acid crystallized out. It was purified from dilute ethyl alcohol. The yield was $13 \mathrm{~g}$. M.P. $137^{\circ}$.

Preparation of the Chloride of a-Picolinic Acid
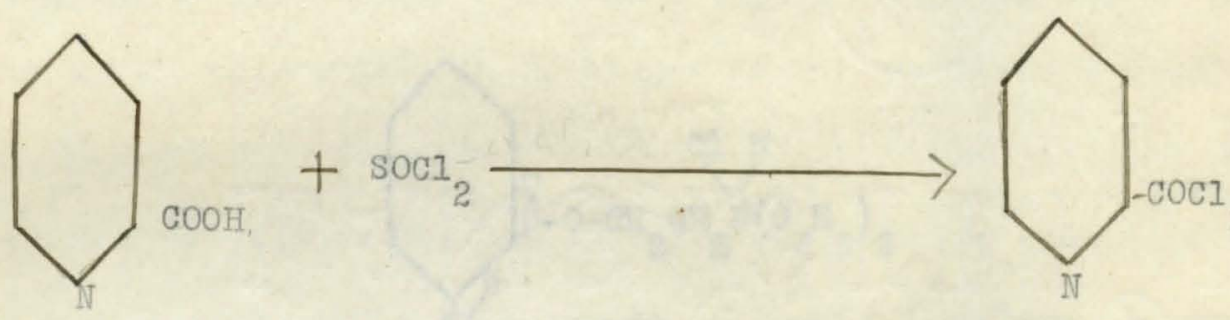

$4 \mathrm{~g}$. of a-picolinic acid were heated on a w ter bath with $20 \mathrm{~g}$. thionyl chloride until the reaction ceased. Benzene was added and the mixture allowed to stand over night. In the morning this was refluxed for one hour on a water bath and wos filtered while hot. On cooling the chloride crystallized out and was filtered off. The yield was 2.5 g. M.P. $125^{\circ}-127^{\circ}$. Preparation of Di-ethyl amino Ethyl Picolinate

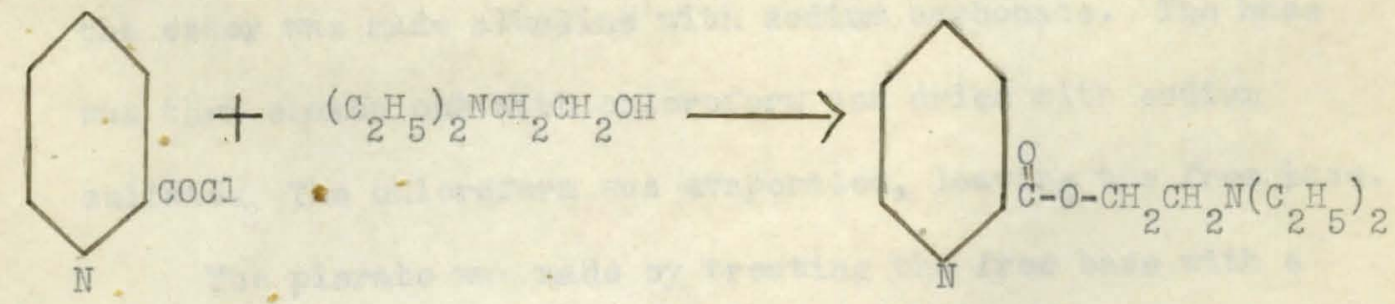

To the chloride of a-picolinic acid, diethylamino othanol 
was added and refluxed with a small amount of ether for 2 hours. The ether was evaporated, leaving a brown semi-solid substance found to be very soluble in alcohol, but not very soluble in ether. The product was recrystallized from dry ether. The yield was 1.5 g. M.P. $126 \stackrel{\circ}{1} 127^{\circ}$.

A chlorine determination showed that the ester contained 2 molecules of chlorine, proving that an HCl group was attached to each nitrogen atom according to the following structure.

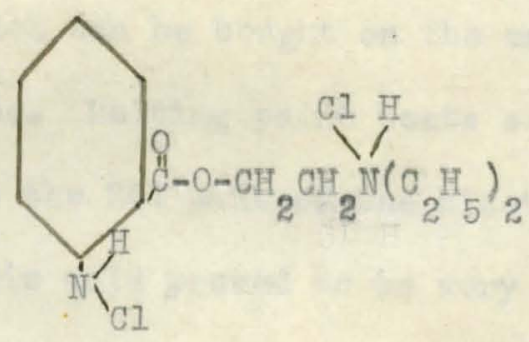

The theoretical per cent calculated for 2 chlorine atoms was $24.06 \%$. T he practical per cents were $22.18 \%$ and $22.47 \%$ for the first determination. In the second determination the practical per cents were 23.6 . $\%$ and $24.00 \%$. - The free base was also prepared and from it the picrate was made. The free base was made as follows. The solution of the ester was made alkaline with sodium carbonate. The bese was then shaken out with chloroform and dried with sodium sulfate. The chloroform was evaporated, leaving the free base. The picrate was made by treating the free base with a saturated solution of picric acid in ether. M.P. $79^{\circ}-80^{\circ}$. It was found to be impossible to prepare the picrate from the HCl salt of the ester, and consequently the free base had to 
be made.

\section{Nicotinic Acid}

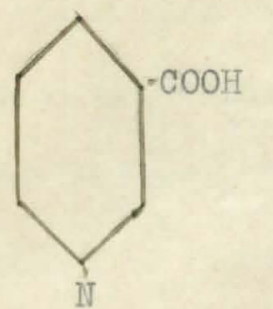

The attempt to prepare the chloride of b-pyridine cerboxylic acid or nicotinic acid was unsuccessful, for the HCl salt of nicotinic acid which can be bought on the market is not affected by thionyl chloride. Melting point tests showed that the ond product was always the HCl salt of the nicotinic acid used in the beginning. This acid proved to be very difficult to obtain in the free state minus the HCl group. Repented attempts to decompose the HCl selt with copper sulfate and hydrogen sulfide were unsuccessful. 
CONCLUSIONS 


\section{Conclusions}

The chlorides of the acids, a-quinoline carboxylic, g-quinoline carboxylic, a-picolinic, and nicotinic, may be prepared rather easily, but not in quantitative yields. Furthermore, they are very difficult to purify from the dye which is formed at the same time that the chloride is prem pared and which is soluble in the benzene from which the chloride must be purified. The chloride when once prepared is rather unstable and decomposes if heated too long on a water bath. Samples of the chlorides when lcept in a vacuun over KOH sticks and parrifin showed a decided tendency to decompose with the formation of a dye.

The esters of these chlorides are easily prepared, but unléss made from the pure chloride, ere difficult to purify. The yields wrere not as good as were expected. The esters are somewhat hygroscopic, also, and for this reason are difficult to introduce into a melting point tube unless they are very thoroughly dried first. 


\section{BIBLIOGRAPHY}


1. Journal American Chemical Society. Trans. CXL 11 (1917).

2. " " " $"$ "Pyman 931793 (1908).

3. Ber. 271870 (1894).

4. Organic Medicinal Chemicals. Barrowclifft-Carr Pages 1-7,91-112.

5. Chemisches Central-Blatt, Geigy V.2 P. 927-29 (1900).

6. Ber. Heller V.4:1 2700.

7. Ber. A. Reissert V. 381610 (1905).

8. Chemisches Centre.I-Blatt H.Meyer V.I P. 1052 (1907).

9. Organic Synthesis $V \cdot 5$.

10.Ber. Weidel 121992 (1879). 
PART 2

The OXIDATION OF n-BUTYI THIOCYANATE WITH NITRIC ACID 


\section{OXIDATIOH OF n-BUTYL-THIOCYANATE WITH NITRIC ACID}

The purpose of the following experiments has been to try to oxidize n-butyl-thiocyanate with concentrated nitric acid to n-butyl sulfonic acid. The oxidation proved to be comparatively easy, but the removal of the excess nitric acid from the n-butyl sulfonic acid formed was found to be rather difficult. When two partis concentrated nitric acid were used with one part water, the oxidation was usully all completed after about five hours constant . slow boiling, and the nitric acid was usually all removed after the sulfonic acid solution was evaporated down on a water bath three or four times with about $15 \mathrm{cc}$. of water. When undiluted nitric acid was used, the oxidation was easily accomplished in three hours, but the subsequent removel of the excess nitric acid proved to be almost impossible. Several different methods were tried, among them evaporation on a water bath, heating to boiling with small quantities of water on a sand bath, heating on a water bath while bubbling air through the sulfonic acid solution, and finally steam distillation was tried. Only one of these methods, that of heating the solution on a sand bath, proved successful in removing the excess nitric acid. In this method, however, the solution got so hot that the sulfonic acid partially carbonized. But the remaining sulfonic acid solution after filtration gave no further test for nitric acid.

From the n-butyl sulfonic acid, the sodium salt was prepared, and from this salt, the chloride was very easily made. 
This chloride in ether solution was then treated with ammonia gas and gave the n-butyl sulfonamide. The next compound made was n-butyl p-toluidide, prepored by condensing n-butyl sulfonyl chloride with p-toluidine. The last product prepered was nbutyl sulfonanilide, made by condensing n-butyl sulfonyl chloride with aniline. All of these products were easily made, although their subsequent purification by recrystallization took some time to accomplish.

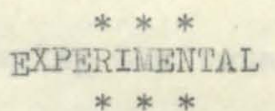

Preparation of n-butyl-thiocyanate $\mathrm{CH}_{3} \mathrm{CH}_{2} \mathrm{CH}_{2} \mathrm{CH}_{2} \mathrm{Br}+\mathrm{NH}_{4} \mathrm{SCN} \longrightarrow \mathrm{CH}_{3} \mathrm{CH}_{2} \mathrm{CH}_{2} \mathrm{CH}_{2} \mathrm{SCN}+\mathrm{NH}_{4} \mathrm{Br}$ Measure $250 \mathrm{cc}$ ethyl alcohol and $20 \mathrm{cc}$. water into a liter R.B. flask and add $84 \mathrm{~g}$. ammonium thiocyanate. Reflux on a water bath with oceasional shaking until the salt is practically dissolved. Add from a separatory funnel during about' I hour the n-butyl bromide. Reflux for 3 hours. Cool and filter off the ammonium bromide on suction, wash with three $50 \mathrm{cc}$. portions of alcohol. Place the alcohol solution in a liter R.B. flask and distill off the alcohol up to $100^{\circ}$ through a distilling column. Then pour into the residue about $300 \mathrm{cc}$. water, causing the n-butyl-thiocyanate to come out as an oil. Separate the layers, wash the oil with three $30 \mathrm{cc}$. portions 
of water and dry over calcium chloride. Distill, collecting at a temperature of $180^{\circ}-187^{\circ}$. The theoretical yield is $115 \mathrm{~g}$. Practical yield $91 \mathrm{~g}$. which was increased $7 \mathrm{~g}$. by the following procedure. Combine the first water layer with the washings and extract with three $50 \mathrm{cc}$ portions of ether. Dry over calcium chloride and distill as before. On dissolving in water the calcium chloride used in the 2 drying processes, the oil which had been absorbed by the calcium chloride, separated out and was carefully collected. This procedure yielded another $4 \mathrm{~g}$. of $\mathrm{n}$ butyl-thiocyanate, bringing the total yield up to $88.69 \%$. An attempt to recover more oil from the alcohol solutions was not very successful, for although the addition of large quantities of water to the alcohol threw a small amount of oil out of solution, the oil did not separate out in large enough quantities to permit its recovery.

Preparation of n-Butyl Sulfonic Acid

$\mathrm{CH}_{3}\left(\mathrm{CH}_{2}\right)_{3} \mathrm{SCN}+\mathrm{HINO}_{3} \longrightarrow \mathrm{CH}_{3}\left(\mathrm{CH}_{2}\right)_{3} \mathrm{SO}_{3} \mathrm{H}$

A mixture of $5 \mathrm{cc}$ n-butyl-thiocyanate, $20 \mathrm{cc}$. concentrated nitric acid, and $10 \mathrm{cc}$. water was heated in a flask loosely closed with a test tube which was converted into a miniature water condenser by means of a 2 holed rubber stopper and some tubing. A very low flame was used to prevent the mixture from boiling too violently and sending nitric oxide fumes into the air. After about 5 hours boiling no trace of n-butyl-thiocyanate remained. The contents of the flask were emptied into a small evaporating dish and 
evaporated down to about $10 \mathrm{cc}$. three times with the addition of $15 \mathrm{cc}$. woter each time until a ferrous sulfate ring test showed that no more nitric acid was present. Then the residue was diluted with about $15 \mathrm{cc}$. water and after cooling was carefully neutralized with a concentrated solution of sodium carbonate, using three drops of phenolphthalein as an indicator. Upon evaporation of this neutral solution to dryness on a water bath, a white solid remained which was sodiun n-butyl sulfonate. Theoretical yield $6.5 \mathrm{~g}$. Practical yield $6 \mathrm{~g}$.

The third time the oxidation was tried $20 \mathrm{cc}$. of concentrated nitric acid were substituted for the nitric acid and water mixture used in the first 2 experiments. Exactly the same procedure was followed as in the first oxidation. At the end of 3 hours, however, the oxidation was complete. The removal of the nitric acid then caused quite a bit of trouble. On evaporation with water for the sixth time, the ring test was very faint and it was decided to proceed with neutralizing the acid. But on evaporation of the solution of the sodium salt a residue weighing $11 \mathrm{~g}$. resulted. A second check experiment run under the same conditions with the same quantities yielded $10.5 \mathrm{~g}$. of sodium n-butyl sulfonate, shovring that either water of crystallization or some sodium nitrate were present in the residue. To test for water of crystallization, I g. of the solid was cerefully heated in an electric oven for several hours at a temperature of $125^{\circ}$. On weighing again, the salt had not lost weight appreciably. It was then heated for 2 hours at a 
temperature of $162^{\circ}$. A third weighing showed no loss of weight large enough to be attributed to water of crystallization. In the meanwhile a small portion of the salt was dissolved in water and a ring test was made which showed a decided brown coloration, showing that a considerable amount of nitrate was in the solution. A test for excess carbonate used in neutralizing also gave a slight test, proving that the abnormal weight of the residue was due to sodium carbonate and sodium nitrate.

The third time this oxidation experiment was run, the resulting sulfonic acid solution was heated on a water bath while a constant stream of air was being forced through the acid solution in an attempt to carry off the excess nitric acid. This was done for 2 days or about 14 hours. At the end of this time the solution still gave a very decided ring test with diphenylamine in concentrated sulfuric acid, and also gave the ferrous sulfote ring test for nitric acid. The air method was then abandoned and a steam distillation for the removal of nitric acid was tried. After 5 hours the distillate no longer gave a nitric acid test, but on testing the liquid remaining in the distilling bulb, a strong nitric acid test resulted, showing that the n-butyl sulfonic acid still contained some nitric acid. The steam distillation was then discontinued.

In a fourth oxidation the n-butyl sulfonic acid solution was boiled gently on a sand bath to remove the nitric acid. After 3 hours boiling the solution got too hot, and the n-butyl sulfonic acid partially decomposed, probably into carbon, sulfur dioxide 
and water. About $5 \mathrm{cc}$. of the black mixture which remained was carefully filtered and was then tested for nitric acid. The results were negative showing that the nitric acid had finally been removed. Boiling gently. on a sand bath, is probably the best method for removing the nitric acid, but great care must be taken not to allow the solution to become too coneentrated or too hot or the n-butyl sulfonic acid will decompose.

Preparation of n-Butyl Sulfonyl Chloride

$\mathrm{CH}_{3}\left(\mathrm{CH}_{2}\right)_{3} \mathrm{SO}_{3} \mathrm{Na}+\mathrm{PCl}_{5} \longrightarrow \mathrm{CH}_{3}\left(\mathrm{CH}_{2}\right)_{3} \mathrm{SO}_{2} \mathrm{Cl}+\mathrm{NaCl}+\mathrm{POCl}_{3}$

Six grams of sodium n-butyl sulfonate were mixed in a

flask with $7.8 \mathrm{~g}$. phosphorous pentachloride and about $3 \mathrm{cc}$ of phosphorous oxychloride were added. After a few minutes stirring the mixture was heated on a water bath at $70^{\circ}-80^{\circ}$ for $4-5$ hours. If heated at a higher temperature the sulfonyl chloride tends to decompose. The semisolid mass which resulted was poured into ice water and the n-butyl sulfonyl chloride came out as a heavy yellowish oil. This was separated from the solution by means of a separatory funnel and was washed 3 times with water. The chloride was prepared 5 times and no difficulty was ever encounteredin obtaining it.

Preparation of $\mathrm{n}$-Butyl Sulfonamide

$\mathrm{CH}_{3}\left(\mathrm{CH}_{2}\right)_{3} \mathrm{SO}_{2} \mathrm{Cl}+\mathrm{NH}_{3} \longrightarrow \mathrm{CH}_{3}\left(\mathrm{CH}_{2}\right)_{3} \mathrm{SO}_{2} \mathrm{NH}_{2}+\mathrm{NH}_{4} \mathrm{Cl}$ The n-butyl sulfonyl chloride was dissolved in $50 \mathrm{cc}$. ether, and was dried over sodium sulfate for severel hours with shaking. It was then filtered and the sodium sulfate was washed with 5 to $10 \mathrm{cc}$. of dry ether. Into this ether solution dry ammonia gas was passed for 2 hours. The ammonium chloride was 
was filtered from the ether solution and ammonia gas was again passed into the ether until no more amonium chloride precipitated out. The solution was then filtered and the ether allowed to evaporate in the air. A yellowish liquid which crystallized when put into the ice box remained. This solid was recrystallized from a mixture of equal parts ether and ligroin. The n-butyl sulfonamide came out in glistening white plates. M.P. $45^{\circ}$. The amide was found to be very soluble in water and ethyl alcohol and insoluble in ligroin.

Preperation of n-Butyl Sulfon p-Toluidide $\mathrm{CH}_{3}\left(\mathrm{CH}_{2}\right)_{3} \mathrm{SO}_{2} \mathrm{Cl}+\mathrm{NH}_{2} \mathrm{C}_{6} \mathrm{H}_{4} \mathrm{CH}_{3}(\mathrm{p}) \longrightarrow \mathrm{CH}_{3}\left(\mathrm{CH}_{2}\right)_{3} \mathrm{SO}_{2} \mathrm{NH}-\mathrm{C}_{6} \mathrm{H}_{4} \mathrm{CH}_{3}(\mathrm{p})+\mathrm{HCl}$

Five grams n-butyl sulfonyl chloride were mixed with $34 \mathrm{~g}$. p-toluidine and $100 \mathrm{cc}$. of $10 \%$ sodium hydroxide. This was shaken until the toluidine dissolved. It was then heated on a water bath for several hours. The mixture was acidified and the amide which separated out was filtered off. The nbutyl sulfon p-toluidide was recrystallized from a mixture of equal parts of alcohol and water. The amide was very soluble in ether and alcohol, slightly soluble in ligroin and insoluble in water. The yield by this method was very small. M.P. $74^{\circ}$.

A second preparation of n-butyl sulfon p-toluidide was done in the following manner. 1Ig of crude sodium n-butyl sulfonate were converted into the chloride and this chloride dissolved in ether was treated with $6.8 \mathrm{~g} \cdot \mathrm{p}$-toluidine in the cold. After a few minutes a white substance precipitated out 
which was probably the HCl salt of p-toluidine since it was very soluble in water. The ether solution was refluxed for an hour on a water bath. After filtering off the white solid, the ether solution was washed several times with water and then with dilute HCl to remove any traces of p-toluidine. Upon evaporation of the ether a brownish oil wos left which became solid when washed with dilute HCl. This solid was dissolved in 3 parts ethyl alcohol and 1 part water and refluxed with charcoal for $\frac{1}{2}$ hour. On filtering and cooling needle-like crystals appeared. These were slightly yellow and had to be recrystallized. After repeated trials the best materials to use for recrystallization seemed to be a mixture of equal parts ethyl alcohol and water. The final product consisted of veyy smalz white needle-like crystals rather light in weight. M.P. $74^{\circ}$. Yield $2 \mathrm{~g}$.

A Kjeldahl determination of the amino nitrogen present in the n-butyl sulfon p-toluidide prepared by the above method gave the following results. Theoretical $6.16 \%$ Practical $5.37 \%$ and $5.66 \%$.

Preparation of $n$-Butyl Sulfon Anilide $\mathrm{CH}_{3}\left(\mathrm{CH}_{2}\right)_{3} \mathrm{SO}_{2} \mathrm{Cl}+\mathrm{C}_{6} \mathrm{H}_{5} \mathrm{NH}_{2} \longrightarrow \mathrm{CH}_{3}\left(\mathrm{CH}_{2}\right)_{3} \mathrm{SO}_{2} \mathrm{NH}_{2} \mathrm{C}_{6} \mathrm{H}_{5}+\mathrm{HCl}$

The last compound prepared was made by condensing the n-butyl sulfonyl chloride with aniline in ether solution. About $6 \mathrm{cc}$. of the chloride were dissolved in $50 \mathrm{cc}$. of ether and $6 \mathrm{~g}$. of aniline were added in the cold. This mixture was then filtered with suction to remove the aniline HCl formed in the process. The 
ether solution was washed 3 times with water and a little dilute HCl to remove any traces of aniline. Upon evaporation of the ether a dark brown oil remained which was dissolved in 3 parts ethyl alcohol to 1 part water and was then refluxed with charcoal for $\frac{1}{2}$ hour on a weter bath. After filtering off the charcoll the solution was allowed to cool. A brown heavy oil separated out. Several attempts to purify this oil were made by dissolving it in small quantities of a mixture of equal parts alcohol and water, refluxing on a water bath and then filtering while hot and after cooling putting the solution in a freezing mixture. By repeating this procedure several times, the oil finally became light tan in color and was left in this state.

\section{Conclusions}

n-Butyl-thiocyanate can exsily be oxidized by concentrated. nitric acid. Apparently the more dilute the acid, the longer time taken for oxidation. On the other hand the more concentrated the nitric acid used, the more difficult it is to remove the excess nitric acid. The best concentration of acid to use appears to be 2 parts concentrated nitric acid to 1 part water. The best method for removing the excess nitric acid in this case is to evaporate the sulfonic acid solution several times with a small amount of water. But if a shorter time is desired for the oxidation, pure concentrated nitric acid is used and then the best way to remove the excess nitric acid is to evaporate the sulfonic acid solution very carefully on a sand bath. 
Due to the comparative instability of the n-butyl sulfonic acid formed by the oxidation of n-butyl-thiocyanate, no attempt was made to distill this acid, but the sodium salt was prepared as soon as all the excess nitric acid had been removed.

The n-butyl sulfonyl chloride can be easily prepared from the sodium n-butyl sulfonate by treating this salt with phosphorous pentachloride. The chloride is insoluble in end heavier than water.

A very good method for the preparation of n-butyl sulfonamide is to pass dry ammonia gas into a dried ether solution of $n=$ butyl sulfonyl chloride.

The best method to prepare the n-butyl sulfon p-toluidide is to dissolve p-toluidine in an ether solution of n-butyl sulfonyl chloride. The dark oil, although rather difficult to purify, may be recrystallized until clear white crystals are obtained from a mixture of equal parts ethyl alcohol and water.

The n-butyl sulfon anilide may be prepared in exactly the same way.as the n-butyl sulfon p-toluidide, by merely substituting aniline for p-toluidine. 
BIBLIOGRAPHY 


\section{BIBLIOGRAPHY}

1. Beilstein, Band 4, p. 8 .

2. Chemisches Zentralblatt, 1906, 1, 1529. Duguet.

3. Berichqte 5,978. Mylius.

4. Berichte 10, 942. Pauly.

5. Journal American Chemical Society, July, 1923, p. 1744-1752. Kaufmen, R.J. and Adams, Roger.

6.Journal American Chemical Society. V. 36, p. 372 (1914). Johnson andAmbler. 